\title{
STUDY OF MORPHOLOGY OF FISSURES OF LUNG IN CENTRAL KARNATAKA REGION
}

\author{
Siri.A.M ${ }^{1}$, Ravikumar *2 \\ ${ }^{1}$ Professor, Department of Anatomy, SUIMS. \& R.C. Purle, Shimoga, Karnataka, India. \\ ${ }^{* 2}$ Professor \& HOD, Department of Anatomy, SUIMS. \& R.C. Purle, Shimoga, Karnataka, India.
}

\section{ABSTRACT}

The adult human lungs are two in number, the right $\&$ left lungs which are concerned with the aeration and exchange of gases. The right lung is comparatively larger $\&$ heavier and has 2 fissures oblique fissure $\&$ horizontal fissure $\&$ has 3 lobes in it. The left lung is longer $\&$ has only 1 fissure in it with 2 lobes.

The present study was done on adult lungs in the Dept. of Anatomy SUIMS \& R.C. Shimoga where only the oblique fissure was seen and horizontal fissure were missing in 7 out of 40 right lungs studied. Incomplete horizontal fissures were in 3 right lungs out of 40. Accessory fissure was seen in 1 specimen of right lung. Accessory fissures were seen in 3 out of 40 left lungs studied. The presence of normal fissures in lung will help in proper expansion of lungs $\&$ also helps in localising the lesions to specific areas in the lungs. Incidence of absence of fissures in lungs varies from one geographical region to other region and is variable with the samples collected by different workers for the study.

The incomplete fissures when present give a atypical appearance of the pleural effusion and may also alter the usual patterns of collapse of the lungs. The knowledge of such absence or incomplete fissures in lungs is helpful for anatomists, radiologists and surgeons operating on lungs during lobar resections of the lung.

KEY WORDS: Fissures Of Lung, Absence Of Fissures, Incomplete Fissure, Lobectomy Of Lung.

Address for Correspondence: Dr. Ravikumar, Professor \& HOD, Department Of Anatomy, Subbaiah Institute of Medical Sciences and Research Center, NH -13, Holehonnur Road, Purle, Shimoga, Karnataka, India-577222.PH : 09844427990,09743491930. E-Mail: drravikumar.rk79@gmail.com

Access this Article online Quick Response code

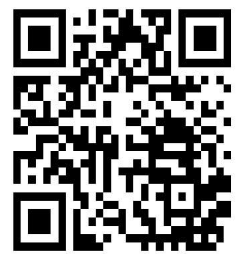

DOI: $10.16965 /$ ijar.2018.300

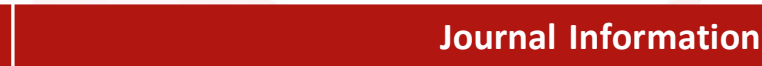

International Journal of Anatomy and Research

ICV for 2016 ISSN (E) 2321-4287 | ISSN (P) 2321-8967

https://www.ijmhr.org/ijar.htm

Dol-Prefix: https://dx.doi.org/10.16965/ijar

Article Information

Received: 27 Jun 2018

Peer Review: 27 Jun 2018

Revised: None
Accepted: $31 \mathrm{Jul} 2018$

Published (O): 05 Sep 2018

Published (P): 05 Sep 2018

\section{INTRODUCTION}

The lungs are organs of respiration. Each lung is divided into lobes by the presence of fissures. The oblique fissure is seen in both right $\&$ left lungs, whereas the horizontal fissure is seen only in right lung. The oblique fissure commences $6 \mathrm{~cm}$ below the apex of the lungs at the level of third or fourth thoracic vertebral spines [1]. It runs along the costal surface $\&$ cuts the inferior border of the lung at the sixth costochondral junction $7.5 \mathrm{~cm}$ from the midline $\&$ ends at the lower end of the hilum [1].
The horizontal fissure overlies the fourth rib to meet the oblique fissure at the level of midaxillary line. The horizontal fissure seperate the superior \& middle lobes ${ }^{1}$. It is present only in the right lung, it passes from the oblique fissure near the midaxillary line horizontally forwards to the anterior border of the lung in level with the sternal end of the fourth costal cartilage [2].

The fissures facilitate the movement of the lobes in relation to one another which accommodates 
the greater distension and movement of the lower lobes during respiration. Thus they help in a more uniform expansion of the whole lung [3]. The fissures may be complete, when the lobes remain held together only at the hilum by the bronchi \& pulmonary vessels. They can also be incomplete when there are areas of parenchymal fusion between the lobes or they may be absent altogether [4].

Similar studies on the morphology of the fissures of lung have been done. In a study by Meenakshi (2003) showed absence of horizontal fissure in $16.6 \%$ of specimens [4]. A study by Vaibhav (2017) showed absence of horizontal fissure in $23.08 \%$ of specimens, incomplete horizontal fissures in $20.51 \%$ of specimens [5]. Study by Vimala (2018) showed absence of horizontal fissure in $2 \%$ of specimens \& incomplete fissures in $68 \%$ of the right fetal lungs [6].

All the data indicate that a thorough knowledge of the absence or incomplete fissures in the lungs are necessary for the anatomists which is of academic significance, to the radiologists as these variations may give atypical appearances in pleural effusions and collapse of the lungs. It is helpful for surgeons operating on lungs during lobectomies as the anatomy of the fissures $\&$ bronchopulmonary segments acts as a guide to delineate the diseased lobe from the normal segment of the lung.

\section{MATERIALS AND METHODS}

The study was conducted in department of Anatomy, SUIMS.\& R.C. Shimoga, Karnataka which included the 80 formalin dried adult lungs [ right sided lungs - 40]; left sided lungs - 40] which were dissected from cadavers. We found that there was absence of horizontal fissure in some specimen, horizontal fissure was incomplete in some right lungs in our study. Accessory fissures were seen in both right \& left lungs in our study. Diseased or pathological lungs were discarded. Details of the fissures \& lobes of the lungs were thoroughly checked and the findings were recorded accordingly.

\section{RESULTS}

Following are the results in the study of fissures of the lung.
Fig. 1: Showing the Absence of the horizontal fissure in the Right lung.

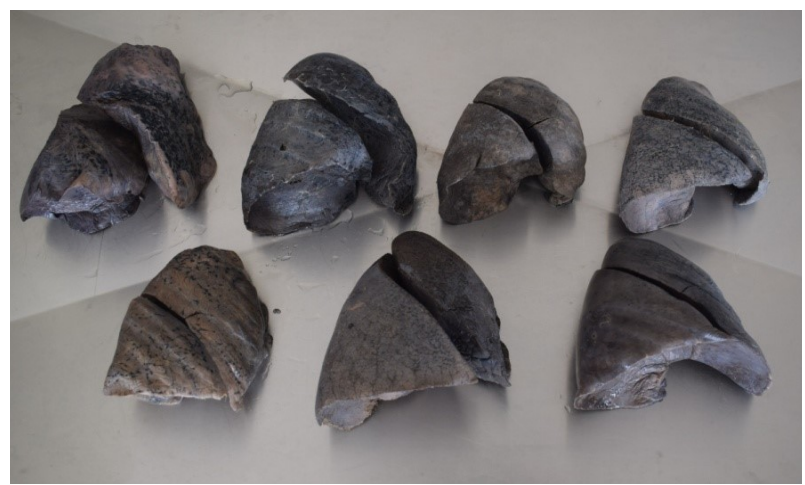

Fig. 2: A, B \& C:- Showing the incomplete horizontal fissures closer to the oblique fissure on the costal surface of the right lung.
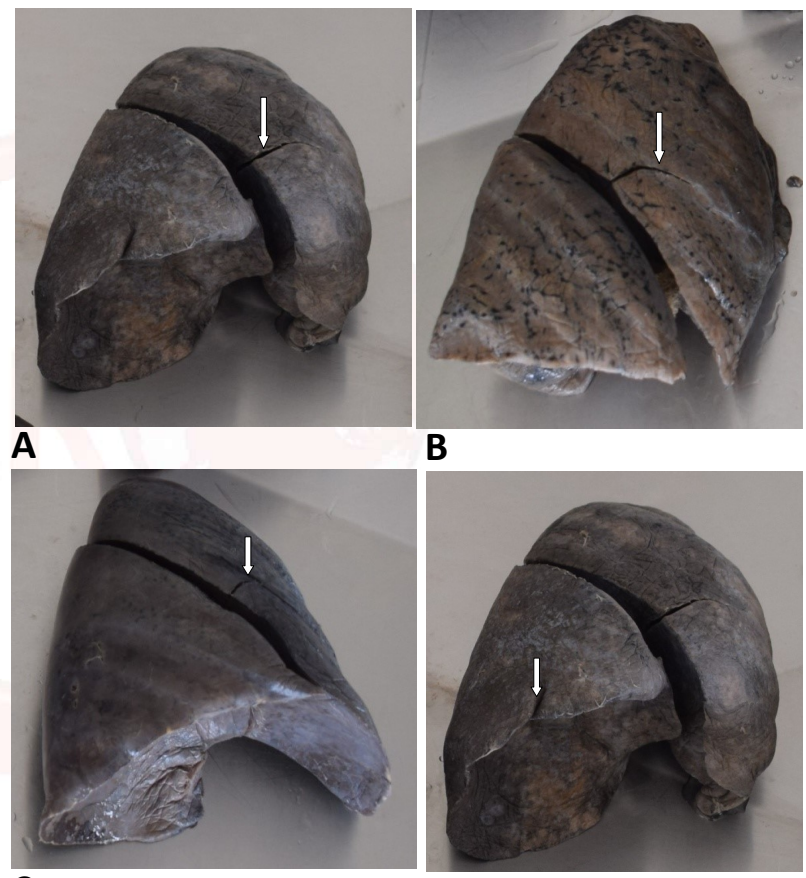

C

D

The number of specimens studied -80 , out of which right sided lungs were $40[n-40]$ left sided lungs were 40 [n-40].

Of the right lungs which were studied 7 were found having the absence of the horizontal fissure ie $\mathbf{1 7 . 5} \%$ Fig : 1 shows the right lungs with absence of horizontal fissure in them.[ Table 1].

The horizontal fissure was observed to be incomplete in $\mathbf{3}$ of the right lungs which were studied. ie. 7.5\% Fig 2 A,B,C, shows the right lungs with incomplete horizontal fissure in the costal surface. [Table 2].

Accessory fissure was seen on inferior surface of the right lung in $\mathbf{1}$ specimen [2.5\%] Fig 2. D - Showing the accessory fissure in the inferior surface of right lung. [ Table 2] 
Accessory fissure was seen on inferior surface of the left lung in 3 specimens [7.5\%]

Table 1: Showing presence or absence of oblique \& horizontal fissures.

\begin{tabular}{|c|c|c|c|c|}
\hline & & Present & Absent & Percentage \\
\hline \multirow{3}{*}{ Right lung [ $n-40]$} & Oblique fissure & 40 & -- & -- \\
\cline { 2 - 5 } & Horizontal fissure & 33 & 7 & $17.50 \%$ \\
\cline { 2 - 5 } & Accessory fissure & 1 & -- & $2.50 \%$ \\
\hline \multirow{2}{*}{ Left lung : [ -40$]$} & Oblique fissure & 40 & -- & -- \\
\cline { 2 - 5 } & Accessory fissure & 3 & -- & $7.50 \%$ \\
\hline
\end{tabular}

Table 2: Showing the presence incomplete \& accessory fissures.

\begin{tabular}{|c|c|c|}
\hline & $\begin{array}{c}\text { Right Lung } \\
{[\mathrm{n}--40]}\end{array}$ & $\begin{array}{c}\text { Left Lung } \\
{[\mathrm{n}--40]}\end{array}$ \\
\hline Incomplete fissures & $3[7.5 \%]$ & Nil \\
\hline Accessory fissures & $1[2.5 \%]$ & $3[7.5 \%]$ \\
\hline
\end{tabular}

\section{DISCUSSION}

The study of the fissures and lobes of the lung has been studied by various workers and the results also are varied depending on the sample size as well as the propensity of occurrence of the variations in the samples collected in different areas. Variations can be in the form of either absence of the fissures or the presence of incomplete fissures of lung. This is also associated with the presence of accessory fissures in both the lungs in the studies done by earlier workers.

Embryological Basis: Each lung is having 10 bronchopulmonary segments. During the development of the lung bud the spaces or fissures present which separate the indiviual lobes \& broncho pulmonary segments become obliterated except along the 2 planes which is evident in lungs as oblique \& horizontal fissures. ${ }^{7}$ The right lung bud has 3 bronchial tubes and left has 2 bronchial tubes on subsequent development the stem bronchi divide dichotomously [8].

Craig \& Walker [9] have given a fissural classification of the lungs which considers the degree of completeness of the fissure $\&$ the location of the pulmonary artery. The grades described by them are,

Grade 1: Complete fissure with entirely separate lobes.

Grade 2: Complete visceral cleft but parenchymal fusion at the base of the fissure.

Grade 3: Visceral cleft evident for a part of fissure.
Grade 4: Complete fusion of lobes with no evident fissural line.

In one of the earlier studies by Lukose et al [10] the presence of incomplete \& absent horizontal fissure in right lung was seen in $21 \%$ \& $10.5 \%$ of the cases studied. Incomplete oblique fissure were seen in $5.3 \%$ of the cases [10]. The findings of absent horizontal fissures in right lung are nearer to the present study [17.5\%]. In a study conducted on lungs of South Indian origin by Meenakshi ${ }^{4}$ it was observed that in $15 \%$ of the cases the horizontal fissure was absent which is almost similar to the findings in our study.[ $17.5 \%$ ]. [Table - 1] Incomplete horizontal fissure \& oblique fissure in right were $63 \%$ \& $36 \%$ respectively which is higher compared to the present study. The accessory fissures were seen in $2 \%$ \& $6 \%$ of right \& left lungs respectively [4] which again is nearer to the values in our study [table 2].

In a study by Dhanalakshmi \& workers [11] the absence of horizontal fissure in right lung was found to be $18 \%$ a value in accordance with our study [17.5\%], [table 1] Vaibhav \& workers [5] in their study observed that absence of horizontal fissures in right lung was $23 \%$ of the cases studied, again similar values as seen in our study. Incomplete oblique fissure was seen in $10.2 \%$ \& $5.26 \%$ of cases on right \& left sides respectively. Oblique fissure was seen to be absent in $2.5 \%$ of cases studied by them. A study by Ajay Nene $\&$ workers ${ }^{12}$ showed that absent horizontal fissure in right lung was $14 \%$, which is closer to findings in our study [17.5\%]. Ajay Nene \& workers found the presence of incomplete horizontal fissure was $8 \%$ in the right lung which is $7.5 \%$ in our study. [Table1]. Accessory fissures in the inferior surface of the lungs were seen in $14 \%$ \& $24 \%$ in right \& left lungs respectively [12].

A thorough knowledge of the fissures \& lobes is essential along with the variations listed above while planning a video assisted thoracic surgery [VATS] or a while performing lobectomies on the lung. Grade 1 oblique fissure is easy while doing lobectomy in VATS [11]. Presence of normal lobar pattern with fissures will help the operating surgeons to clearly demarcate the bronchopulmonary segments while doing the lobar resections of the lung. Pulmonary veins 
which are present between the segments act as a guide in removal diseased segments only. In case of absence of fissures there will be presence of Grade 2 to Grade 4 fissures of the lung as described earlier, then the lung parenchyma has to be dissected to reach those structures leading to pre-operative haemorrhage \& post operative complications [11].

Incomplete fissures produce a pseudo appearance of fluid within the fissure. Incomplete fissure may allow the spread of infection to the other lobes of the lungs [4]. Presence of normal fissures in lung enhances the uniform expansion of the lungs \& their position can be used as a reliable landmark in specifying the

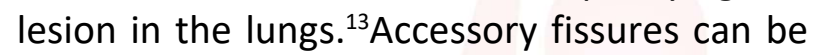
confused with the lung lesions on radiological examination. Accessory fissures acts as a barrier in spreading the infection which can be misinterpreted as atelectasis, consolidation of lung or lung scar [1].

\section{CONCLUSION}

The occurrences like absence of fissures, incomplete fissures \& accessory fissures in lung have different results in different studies done which is again varied depending on the samples collected in that particular area of the study. In our study the occurance of absence of horizontal fissure in right lung was seen in accordance with earlier studies. Absence of oblique fissures was not observed in either right or left lungs studied. Incomplete fissures were seen right lung $\&$ accessory fissures were seen in right \& left lungs. But the knowledge of such types of variations is essential to the anatomists as the findings are of academic significance. These facts are helpful for the surgeons who are operating on the lungs to anticipate the possible postoperative complications and the understanding of these types of variations is necessary to the radiologists to interpret the test results correctly and not confusing them for atypical pleural effusion or the collapse of the lung.

\section{Conflicts of Interests: None}

\section{REFERENCES}

[1]. Standring. S. Borley N.R, Collins.P. Gray's Anatomy The anatomical basis of Clinical Practice. Pleura, lungs, trachea and bronchi. $40^{\text {th }}$ edition, Spain, Churchill Livingstone; 2008;993-998.

[2]. Dutta. A.K., Essentials of Human Anatomy, Vol 1, Current Books International, Kolkata, 2004;27-28.

[3]. Roose. C. Gaddam - Roose. P. Thorax: Hollinshead"s Text book of Anatomy, $5^{\text {th }}$ edition: Philidelphia; Lippincotts; Raven; 1997;441-461.

[4]. Meenakshi. S. Manjunath.K.Y., Balasubramanyam.V. Morphological variations in lung fissures \& lobes; Indian journal of Chest Diseases \& Allied Sciences; 2004;46:179 - 182.

[5]. Vaibhav Prakash Anjankar, Kanchana P.Wankhede, Ashutosh. S. Mangalagiri, Morphological study of Lung Lobes \& fissures; Anatomical basis of surgical \& imaging techniques. International journal of anatomy \& research;2017;5(1):3447-50.

[6]. Vimala .V. Jamuna. M. Nirmaladevi. M. Amudha. G. Morphological study of fissures and lobes in fetal lungs. International Journal Of Anatomy \& Research 2018;6(1.2):4959-62.

[7]. Larsen WJ, Human Embryology, NewYork; Churchill Livingstone; 1993;111-30.

[8]. Hamilton W.J., Mossman H.W. Human Embryology prenatal development of form $\&$ function. $4^{\text {th }}$ edition, Macmillan Press Itd; London; 1976;328-330.

[9]. Craig S.R. Walker W.S.A proposed anatomical classification of the pulmonary fissures. J.R.Coll.Surg. Edinburgh 1997;42;233-234.

[10]. Lukose .R. Paul.S. Sunitha et al Morphology of the lungs; Variations in the lobes and fissures. 1999;19:227-232.

[11]. Dhanalakshmi V. Manmohan C., Rajesh R., Suba Ananthi.K, Morphological study of fissures \& lobes of the lungs; Intl J Anat \& research; 2016;4(1):189295.

[12]. Nene A.R, Gajendra K.S, Sarma MVR, Lung lobes and fissures; a morphological study; International journal of experimental and clinical anatomy; 2011;5:30-38.

[13]. Kent E.M, Blades B. The surgical anatomy of pulmonary lobes; Journal of Thoracic surgery; 1942;12:1830.

[14]. Godwin J.D, Tanveer R.D, Accessory fissures of the lung; Am J Roentgenology; 1985;144;39-47.

How to cite this article:

Siri.A.M, Ravikumar. STUDY OF MORPHOLOGY OF FISSURES OF

LUNG IN CENTRAL KARNATAKA REGION. Int J Anat Res

2018;6(3.3):5643-5646. DOI: 10.16965/ijar.2018.300 